\title{
Confidence in Prescription Writing among Junior Physicians in Trinidad and Tobago
}

\author{
D Ignacio ${ }^{1}, \mathrm{P} \mathrm{Sealy}^{1}, \mathrm{Y} \mathrm{Clement}^{2}$
}

\begin{abstract}
Background: A fundamental skill in the practice of medicine is the ability to safely and rationally prescribe drugs. This research aims to estimate the percentage of newly registered medical officers who reported confidence in writing prescriptions.

Methods: A questionnaire was distributed to 200 medical officers employed at public health tertiary institutions throughout Trinidad and Tobago. These comprised medical interns (provisionally registered) and house officers (fully registered). Participants indicated their confidence or reluctance to prescribe with or without supervision. Estimates and comparisons between the two groups were obtained using Fisher's exact and Chi-square tests.

Results: The response rate was 73.5\%. More medical interns $(68 \% ; n=41)$ than house officers $(56 \%$; $n=42)$ stated that they were 'Confident' or 'Very Confident' $(\mathrm{p}=0.126)$ to prescribe. Approximately eighty-four per cent (83.6\%; $n=51)$ of medical interns and $89.2 \%(n=66)$ of house officers felt confident to prescribe antibiotics $(p=0.465)$. A greater percentage of medical interns $(84.2 \% ; n=50)$ than house officers $(66.7 \% ; n=49)$ agreed that undergraduate training equipped them to write prescriptions safely and rationally $\left(\chi^{2}=6.17, d f=1 ; \mathrm{p}=0.012\right)$.

Conclusions: While most recent medical graduates felt confident about their prescription writing, there is a need to objectively measure this ability.
\end{abstract}

Keywords: Clinical pharmacy and therapeutics, medical curriculum, prescription writing

\section{Seguridad al Escribir Prescripciones entre los Médicos Jóvenes en Trinidad y Tobago D Ignacio ${ }^{1}$, P Sealy ${ }^{1}, \mathrm{Y} \mathrm{Clement}^{2}$}

\begin{abstract}
RESUMEN
Antecedentes: Una habilidad fundamental en la práctica de la medicina es la habilidad de prescribir medicamentos de forma segura y racional. Esta investigación persigue estimar el porcentaje de funcionarios médicos recién registrados que reportaron sentirse seguros a la hora de escribir recetas médicas. Métodos: Se distribuyó un cuestionario a 200 oficiales médicos empleados en instituciones de enseñanza superior de salud pública en Trinidad y Tobago. Se trataba de médicos internos (provisionalmente registrados) y residentes (completamente registrados). Los participantes indicaron su confianza o su reticencia en cuanto a prescribir con o sin supervisión. Los estimados y comparaciones entre los dos grupos fueron obtenidos mediante pruebas de Chi cuadrado y el test exacto de Fisher.

Resultados: La tasa de respuesta fue 73.5\%. Más médicos internos $(68 \% ; n=41)$ que residentes $(56 \%$; $n=42)$ declararon que se sentían 'seguros' o 'muy seguros' $(\mathrm{p}=0.126)$ a la hora de prescribir. Aproximadamente ochenta y cuatro por ciento $(83.6 \% ; n=51)$ de los médicos internos y $89.2 \%(n=66)$ de los residentes se sentían confiados a la hora de prescribir antibióticos $(\mathrm{p}=0.465)$. Un mayor porcentaje de médicos internos $(84.2 \% ; n=50)$ que de residentes $(66,7 \% ; n=49)$ estuvo de acuerdo en que la formación de pregrado les preparó para escribir recetas médicas de forma segura y racional $\left(\chi^{2}=6.17\right.$, $d f=1 ; \mathrm{p}=0.012$ ).

Conclusiones: Aunque la mayoría de los médicos recién graduados se sentían confiados con respecto a escribir prescripciones, es necesario medir objetivamente esta habilidad.
\end{abstract}

From: ${ }^{1}$ School of Pharmacy, ${ }^{2}$ Pharmacology Unit, Faculty of Medical Sciences, The University of the West Indies, St Augustine, Trinidad and Tobago.
Correspondence: Dr DN Ignacio, School of Pharmacy, Faculty of Medical Sciences, The University of the West Indies, St Augustine, Trinidad and Tobago. Fax: 868 662-1472; e-mail: Diane.ignacio@sta.uwi.edu 
Palabras claves: Farmacia clínica y terapéutica, currículo médico, escritura de prescripciones

West Indian Med J 2015; 64 (4): 408

\section{INTRODUCTION}

A fundamental skill in the practice of medicine is the ability to safely and rationally prescribe drugs. Ideally, the prescriber's intention to treat must be congruent with the written script. A sound knowledge of the pathophysiology of diseases and clinical pharmacology and therapeutics are essential for safe and rational prescribing (1). Studies have shown marked discrepancies between the prescriber's intent to treat and the actual written script, especially among junior doctors $(1,2)$. Medication errors in hospitalized patients are common and many are preventable (3). Bates et al suggest that prescribing errors account for more than half of all significant but preventable adverse drug reactions (4). These errors are more likely to occur when the prescriber lacks relevant knowledge about the drug or the patient. Errors lead to unsafe and ineffective treatment which can prolong illness, lengthen hospitalization and even cause death (5). It has also been suggested that medical doctors may be vulnerable to irrational prescribing if not adequately trained in rational pharmacotherapy (5). The literature suggests that medical schools should incorporate clinical pharmacology and therapeutics (CPT) training in the curriculum to improve the prescribing practices among medical graduates (6-8).

In the English-speaking Caribbean, the Bachelor of Medicine, Bachelor of Surgery (MB BS) degree is offered at The University of the West Indies (UWI) and the full five-year programme is taught at the Faculty of Medical Sciences at three campuses (Trinidad and Tobago, Jamaica, and Barbados). Students at these campuses also have the option to complete the MB BS at the fourth campus in The Bahamas, once they have successfully completed the preclinical years. A medical intern (MI), who has successfully attained the MB BS degree, is provisionally registered with the Medical Board of Trinidad and Tobago (MBTT). The MIs are required to complete an internship programme consisting of four rotations (medicine, surgery, obstetrics and gynaecology, and paediatrics) for three months each at public tertiary hospitals throughout Trinidad and Tobago. Satisfactory completion of the rotations would result in full registration by MBTT and qualification to become a house officer (HO). While the current medical curriculum does not have a dedicated CPT course, interactive teaching methods such as problem-based learning (PBL) are employed and may be the students' initial exposure to prescription writing.

Studies have shown that interns are not sufficiently trained to prescribe during the formal undergraduate medical curriculum. As described in the literature, newly graduated interns are required to prescribe potent drugs from the first day of clinical practice. Consequently, inappropriate prescribing habits may lead to ineffective and unsafe treatment when pres- cribing decisions are relegated to junior clinicians (9-11). There is also an increased demand on newly graduated physicians to prescribe from an ever expanding formulary. Junior clinicians must be familiar with important drug-drug interactions associated with polypharmacy (multiple medications on a prescription or used by a patient), and be aware of prescribing guidelines in the elderly and other vulnerable (specialized) populations and more complicated therapeutic regimens (11). Newly graduated interns in Trinidad and Tobago are allowed to prescribe from the first day of clinical practice. In light of this, the purpose of the survey was to estimate the percentage of newly registered MIs and HOs who report being confident with respect to writing prescriptions. We also determined the specific classes of drugs and special patient populations for which they were confident to write prescriptions. Additionally, we sought to find out if junior physicians witnessed adverse drug reactions (ADRs) during their duties, the outcomes of the ADRs, and whether these events were avoidable, predictable or unpredictable.

\section{SUBJECTS AND METHODS}

The study used a cross-sectional survey design to distribute 200 questionnaires to MIs and HOs working in the public health sector between July 2010 and January 2011. Eligible MIs refer to medical school graduates who obtained the MB BS degree, and were registered provisionally with the MBTT. House officers refer to those who had completed the internship period and acquired full registration with the MBTT. Selection was by convenience sampling since it was not possible to construct a sampling frame and use random sampling.

The 200 self-completed questionnaires were distributed on site during working hours. To avoid the possibility of any one person completing more than one questionnaire, a single research assistant distributed and retrieved the questionnaire from each participant. The questionnaire was patterned after a similar instrument used in a previous study conducted among medical doctors in the first year of their employment (12). Prior to distribution, the questionnaire was pre-tested and some items were then revised to increase the reliability of the instrument and data precision. The final version of the 31-item questionnaire consisted of a mixture of closed-ended and openended items. However, seven of these 31-question stems were associated with polytomous or open-ended sub-questions. Variables measured included knowledge of CPTs and confidence and reluctance with respect to prescribing various classes of drugs including prescribing for selected patient populations. Information on ADRs was asked using an openended question. The only demographic variables measured were hospital position, age, gender, medical school attended and number of years since graduating with the medical degree. 


\section{Ethics approval}

The study was approved by the Ethics Committee of the Faculty of Medical Sciences, The UWI, St Augustine campus and the Ethics Committees of respective Regional Health Authorities which manage tertiary hospitals throughout Trinidad and Tobago.

\section{Statistical analysis}

Data were analysed using the Statistical Package for Social Sciences (SPSS Inc., Chicago, IL) version 19.0 and Minitab (Minitab Inc., State College, PA) version 16. Both descriptive and inferential methods were used for data analyses. The inferential methods included Fisher's exact and Chi-square of associations between respondent status and level of self-reported confidence, and confidence or reluctance to prescribe with or without supervision.

\section{RESULTS}

The response rate was 73.5\% (147/200) overall. A Cronbach's alpha of 0.84 signified the high reliability of the survey instrument. Table 1 shows the demographic characteristics of the participants. Among respondents, $41.5 \%$ were male and $51.7 \%$ were female. Most respondents $(64.7 \%)$ received their medical degree at either the Trinidad and Tobago or Jamaica campuses of UWI. Most of the respondents were 28 years of age or less $(64.6 \%)$ and had graduated within the last ten years of the implementation of the study $(87.1 \%)$.

Table 1: Demographic characteristics of respondents

\begin{tabular}{lc}
\hline Variable & Number (\%) \\
\hline Hospital position & \\
$\quad$ Intern & $60(40.8)$ \\
$\quad$ House Officer & $74(50.3)$ \\
Gender & \\
$\quad$ Male & $61(41.5)$ \\
$\quad$ Female & $76(51.7)$ \\
Age & \\
$\quad<25$ years & $39(26.5)$ \\
26 to 28 years & $56(38.1)$ \\
$\quad>28$ years & $46(31.3)$ \\
Medical school attended & \\
UWI - St Augustine, Trinidad and Tobago & $88(59.9)$ \\
UWI - Mona, Jamaica & $7(4.8)$ \\
Other medical school & $44(29.9)$ \\
Years since MB BS graduation & \\
$\quad<5$ years & $113(76.9)$ \\
6-9 years & $15(10.2)$ \\
$>10$ years & $16(10.9)$ \\
\hline
\end{tabular}

UWI - University of the West Indies; MB BS - Bachelor of Medicine, Bachelor of Surgery

\section{Self-reported knowledge and confidence}

The difference between the proportion of the MIs $(68 \%$; $n=$ $41)$ and HOs $(56 \% ; n=42)$ who stated that they were 'Confident' or 'Most Confident' to prescribe was not statistically significant $(p=0.126)$. At the same time, more HOs $(81.7 \% ; \mathrm{n}=$ $61)$ than MIs $(74.1 \% ; n=45)$ agreed that confidence was a fac- tor that affected their ability to prescribe drugs safely and rationally $(p=0.393)$. Even though a greater percentage of HOs $(97.3 \%, \mathrm{n}=72)$ than MIs $(89.1 \% ; n=54)$ agreed or strongly agreed that experience affected their ability to prescribe, the difference was not statistically significant ( $p=$ $0.139)$. Conversely, fewer HOs $(85.9 \% ; n=72)$ than MIs $(96.5 \% ; n=58)$ either agreed or strongly agreed that availability of advice from a consultant affected their ability to prescribe. This difference was also not statistically significant $(p=0.650)$.

Twenty-eight (47.5\%) MIs and 23 (31.9\%) HOs rated their current knowledge of CPT as either good or excellent ( $p$ $=0.075)$. Similarly, more MIs $(84.2 \% ; n=50)$ than HOs $(66.7 \% ; n=49)$ tended to agree that undergraduate medical training equipped them to write prescriptions safely and rationally $\left(\chi^{2}=6.17, \mathrm{df}=1 ; p=0.012\right)$. There were no statistically significant differences between the two categories of junior physicians for factors that could affect ability to prescribe such as being in a hurry $(73.6 \%$ vs $81 \%$; $p=0.235)$, being interrupted $(75.3 \%$ vs $68.4 \% ; p=0.344)$, excessive workload $(81.7 \%$ vs $84.4 \% ; p=0.549)$ and being fatigued (79.2\% vs $85.7 \%$; $p=0.428)$ for MIs and HOs, respectively.

\section{Self-reported confidence to prescribe without supervision in special populations}

No statistically significant differences were found in the percentage of HOs and MIs with respect to whether they were 'Confident' or 'Most Confident' to prescribe independently for elderly patients $(48.6 \%$ vs $44.2 \% ; p=0.951)$, for patients with renal disease $(28.9 \% v s 22.4 \% ; p=0.321)$ or for pregnant women $(32.4 \%$ vs $31.6 \%$; $p=0.663)$. Similar results were obtained with respect to confidence to prescribe for children $(30.4 \%$ vs $32.7 \% ; p=0.074)$ and for patients with liver disease $(20.9 \%$ vs $25.0 \% ; p=0.349)$. Table 2 shows that there were no statistically significant differences between the percentages of HOs and MIs with respect to confidence in prescribing for any special population. 
Table 2: Self-reported confidence to prescribe in special populations between interns and house officers

\begin{tabular}{|c|c|c|c|}
\hline Level of confidence & $\begin{array}{c}\text { Medical Intern } \\
\text { n (\%) }\end{array}$ & $\begin{array}{c}\text { House Officer } \\
\text { n (\%) }\end{array}$ & $p$ value \\
\hline \multicolumn{4}{|l|}{ Renal disease patients } \\
\hline Average & $32(55.2)$ & $32(46.4)$ & 0.321 \\
\hline Confident & $13(22.4)$ & $17(24.6)$ & \\
\hline Most confident & $0(0.0)$ & $3(4.3)$ & \\
\hline Overall & $45(77.6)$ & $52(75.3)$ & \\
\hline \multicolumn{4}{|l|}{ Liver disease patients } \\
\hline Average & $26(43.3)$ & $37(55.2)$ & 0.349 \\
\hline Confident & $15(25.0)$ & $13(19.4)$ & \\
\hline Most confident & $0(0.0)$ & $1(1.5)$ & \\
\hline Overall & $41(68.3)$ & $51(76.1)$ & \\
\hline \multicolumn{4}{|l|}{ Children } \\
\hline Average & $24(41.4)$ & $25(36.2)$ & 0.074 \\
\hline Confident & $10(17.2)$ & $18(26.1)$ & \\
\hline Most confident & $9(15.5)$ & $3(4.3)$ & \\
\hline Overall & $43(74.1)$ & $46(66.6)$ & \\
\hline \multicolumn{4}{|l|}{ The elderly } \\
\hline Average & $23(44.2)$ & $31(43.1)$ & 0.951 \\
\hline Confident & $21(40.4)$ & $32(44.4)$ & \\
\hline Most confident & $2(3.8)$ & $3(4.2)$ & \\
\hline Overall & $46(88.4)$ & $66(91.7)$ & \\
\hline \multicolumn{4}{|l|}{ Pregnant women } \\
\hline Average & $25(43.8)$ & $23(33.8)$ & 0.663 \\
\hline Confident & $16(28.1)$ & $18(26.5)$ & \\
\hline Most confident & $2(3.5)$ & $4(5.9)$ & \\
\hline Overall & $43(75.4)$ & $45(66.2)$ & \\
\hline
\end{tabular}

Self-reported confidence and reluctance to prescribe without supervision

Table 3 shows that antibiotics were ranked first among the classes of drugs which both MIs and HOs were most comfortable to prescribe without supervision $(83.6 \%$ vs $89.2 \%$; $p=$ $0.465)$. However, a significantly greater percentage of HOs than MIs were confident to prescribe, without supervision, the following: diuretics $(86.5 \%$ vs $63.3 \% ; p=0.002)$, inhaled steroids $(79.7 \%$ vs $61.7 \%$; $p=0.021)$, insulins $(82.4 \%$ vs 55.0 ; $p=0.001)$, antiplatelets $(71.6 \%$ vs $48.3 \% ; p=0.006)$, antihistamines $(70.3 \%$ vs $48.3 \% ; p=0.010)$, anticoagulants $(66.2 \%$ vs $41.7 \%$; $p=0.006)$ and opioid analgesics $(66.2 \%$ vs $36.7 \%$; $p=0.001)$.

Medical interns were more reluctant than HOs to prescribe antiarrhythmics $(68.3 \%$ vs $43.2 \% ; p=0.004)$, antiparkinson's drugs $(58.3 \%$ vs $44.6 \% ; p=0.114)$, antidepressants $(50.0 \%$ vs $29.7 \% ; p=0.017)$ and anxiolytic drugs $(48.3 \%$ vs $24.3 \%$; $p=0.004)$, without supervision (Table 4).

\section{Witnessed adverse drug reactions}

The difference between the per cent of HOs $(68.9 \% ; n=51)$ and MIs $(58.3 \% ; \mathrm{n}=35)$ who reported witnessing an ADR during their clinical rotations was not statistically significant $\left(\chi^{2}=\right.$ $0.806, \mathrm{df}=1 ; p=0.659)$. In most cases, the respondents were unable to identify the drug responsible for the most severe ad-
Table 3: Self-reported confidence to engage in unsupervised prescribing of various classes of drugs by type of officer

\begin{tabular}{|c|c|c|c|c|}
\hline \multirow[b]{2}{*}{ Drug class } & \multirow[b]{2}{*}{$\begin{array}{c}\text { Overall } \\
\text { n (\%) }\end{array}$} & \multicolumn{3}{|c|}{ Confidence to prescribe: $\mathbf{n}(\%)$} \\
\hline & & $\begin{array}{c}\text { Medical } \\
\text { Intern }\end{array}$ & House Officer & $p$ value \\
\hline Antibiotics & $117(87.3)$ & $51(83.6)$ & $66(89.2)$ & 0.465 \\
\hline PPI & $116(86.6)$ & $50(83.3)$ & $66(89.2)$ & 0.325 \\
\hline Antacids & $103(76.9)$ & $45(75.0)$ & $58(78.4)$ & 0.645 \\
\hline Diuretics & $102(76.1)$ & $38(63.3)$ & $64(86.5)$ & 0.002 \\
\hline Asthma/COPD inhalers & $102(76.1)$ & $41(68.3)$ & $61(82.4)$ & 0.057 \\
\hline Oral hypoglycaemics & $97(72.4)$ & $38(63.3)$ & $59(79.7)$ & 0.035 \\
\hline Antihypertensives & $96(71.6)$ & $38(63.3)$ & $58(78.4)$ & 0.055 \\
\hline Steroids (inhaled) & $96(71.6)$ & 37 (61.7) & $59(79.7)$ & 0.021 \\
\hline Statins & $94(70.2)$ & $39(65.0)$ & $55(74.3)$ & 0.241 \\
\hline Analgesics (non-opioid) & $94(70.2)$ & 37 (61.7) & $57(77.0)$ & 0.053 \\
\hline Insulins & $94(70.2)$ & $33(55.0)$ & $61(82.4)$ & 0.001 \\
\hline $\mathrm{H}_{2}$ blockers & $92(68.7)$ & $38(63.3)$ & $54(72.8)$ & 0.232 \\
\hline Beta-blockers & $92(68.7)$ & $36(60.0)$ & $56(75.7)$ & 0.052 \\
\hline Antifungals & $87(64.9)$ & $33(55.0)$ & $54(73.0)$ & 0.405 \\
\hline Steroids (oral) & $86(64.2)$ & $34(56.7)$ & $52(70.3)$ & 0.103 \\
\hline Antiplatelets & $82(61.2)$ & $29(48.3)$ & $53(71.6)$ & 0.006 \\
\hline Nitrates & $81(60.5)$ & $31(51.7)$ & $50(67.7)$ & 0.061 \\
\hline Antihistamines & $81(60.5)$ & $29(48.3)$ & $52(70.3)$ & 0.010 \\
\hline Anticoagulants & $74(55.2)$ & $25(41.7)$ & $49(66.2)$ & 0.006 \\
\hline Analgesics (opioid) & $71(53.0)$ & $22(36.7)$ & $49(66.2)$ & 0.001 \\
\hline
\end{tabular}

PPI - proton pump inhibitor; COPD - chronic obstructive pulmonary disease

Table 4: Self-reported reluctance to engage in unsupervised prescribing of various drugs or drug classes $(n=134)$

\begin{tabular}{lcccc}
\hline Drug class & \multicolumn{4}{c}{ Reluctant to prescribe: n (\%) } \\
& $\begin{array}{l}\text { Overall } \\
\text { n (\%) }\end{array}$ & Medical Intern & House Officer & $\boldsymbol{p}$ value \\
\hline Antiarrhythmics & $73(54.5)$ & $41(68.3)$ & $32(43.2)$ & 0.004 \\
Thrombolytics & $69(51.5)$ & $33(55.0)$ & $36(48.7)$ & 0.464 \\
Antiparkinson's & $68(50.8)$ & $35(58.3)$ & $33(44.6)$ & 0.114 \\
Antipsychotics & $67(50.0)$ & $30(50.0)$ & $37(50.0)$ & 0.999 \\
Hypnotics & $64(47.8)$ & $33(55.0)$ & $31(41.9)$ & 0.131 \\
Thyroid drugs & $54(40.3)$ & $26(43.3)$ & $28(37.8)$ & 0.519 \\
Antidepressants & $52(38.8)$ & $30(50.0)$ & $22(29.7)$ & 0.017 \\
Antivirals & $49(36.6)$ & $25(41.7)$ & $24(32.4)$ & 0.270 \\
Anxiolytics & $47(35.1)$ & $29(48.3)$ & $18(24.3)$ & 0.004 \\
Anticonvulsants & $30(22.4)$ & $19(31.7)$ & $11(14.9)$ & 0.020 \\
\hline
\end{tabular}

verse effect observed. However, antimicrobial drugs such as penicillins $e g$ augmentin (amoxicillin and clavulanate) were the most commonly stated causal agents that produce allergic responses, including Stevens Johnson syndrome. Other implicated drugs included angiotensin converting enzyme inhibitors, allopurinol and anticonvulsants.

Of the 86 junior physicians who witnessed an ADR, 53 $(61.6 \%)$ reported that the event was avoidable and just about one-half (55.8\%) of the witnesses to these events reported and documented them. The most common outcomes of ADRs were hospitalization and prolonged stay at hospital (Table 5). House officers reported a significantly greater level of morbidity ( $\chi^{2}=6.269, \mathrm{df}=3 ; p=0.012$ ) compared to MIs. Similar numbers of MIs and HOs (14.3\% vs 7.8\%) reported that the 
Table 5: Most severe adverse drug reactions (ADRs) witnessed by type of officer, n (\%)

\begin{tabular}{lccccc}
\hline Outcome & Interns & House Officers & $\chi^{2}$ & df & $\boldsymbol{p}$ value \\
\hline ADR reported & $21(60.0)$ & $27(52.9)$ & 0.038 & 21 & 0.846 \\
& & & & & \\
ADR outcome & & & & & \\
$\quad$ Hospitalization & $11(31.4)$ & $22(43.1)$ & 1.203 & 21 & 0.273 \\
Prolonged hospital stay & $18(51.4)$ & $18(35.3)$ & 2.220 & 3 & 0.136 \\
Morbidity & $3(8.6)$ & $16(31.4)$ & 6.269 & 3 & 0.012 \\
Death & $5(14.3)$ & $4(7.8)$ & 0.919 & 3 & 0.338 \\
& & & & & \\
ADR classification & $22(62.9)$ & $31(57.4)$ & 0.038 & 2 & 0.846 \\
Avoidable & $4(11.4)$ & $9(17.7)$ & 0.626 & 2 & 0.429 \\
Predictable & $10(28.6)$ & $14(27.5)$ & 0.013 & 2 & 0.909 \\
Unpredictable & & & & & \\
\hline
\end{tabular}

most severe ADR witnessed $\left(\chi^{2}=0.919, \mathrm{df}=3 ; p=0.338\right)$ resulted in death of the patient. There were two reports of cardiac arrest leading to death, which involved the concomitant use of a $\beta$-blocker and calcium channel blocker.

\section{DISCUSSION}

To our knowledge, this is the first study of its kind in the English-speaking Caribbean to assess how junior physicians rated their confidence to prescribe. This survey was important as there is a critical need for the faculty at UWI to continually review teaching and learning strategies in order to produce physicians who are "fit-to-practice". The responses of these junior physicians gave insight to what the faculty might do to improve the medical curriculum to adequately prepare graduates capable of prescribing drugs efficiently.

Our findings suggest that most MIs and HOs at tertiary hospitals throughout Trinidad and Tobago felt that they were sufficiently confident to prescribe safely and rationally. Medical interns were generally more likely than HOs to report that they were confident or most confident to prescribe without supervision. However, when asked about specific drug classes, HOs were more confident than MIs to prescribe without supervision and this most likely was directly related to experience.

Specifically, MIs and HOs were very confident to prescribe antibiotics, diuretics, insulins and oral hypoglycaemics without supervision. A similar finding was noted in a pilot study in Nigeria by Oshikoya et al (1). However, unlike the MIs in the Nigerian study, we were unable to correlate confidence with the number of clinical rotations. House officers were more confident than MIs to prescribe to the elderly and for most drug classes. It would be expected that confidence is directly related to clinical exposure. We also noted the high levels of reluctance by these junior clinicians to prescribe antiarrhythmic and central nervous system drugs without oversight; this may reflect their limited exposure to these drugs on the wards or during the curriculum.

Most MIs and HOs surveyed were trained at UWI, either at the St Augustine campus in Trinidad and Tobago or at the Mona campus in Jamaica. At the St Augustine campus, PBL is a key aspect of undergraduate teaching and learning in the first three years. The curriculum in the first two Preclinical Sciences years involves teaching and self-directed learning of basic pharmacology in structured systems-based courses. In the Paraclinical Sciences year (year 3), teaching and learning include an integrated approach in anatomical and chemical pathology, immunology, haematology, microbiology and pharmacology; students are exposed to "virtual" patients in the PBL format. During clinical training, in the final two years, students rotate through the disciplines of Medicine and Therapeutics, General Surgery, Child Health, Obstetrics and Gynaecology, Psychiatry, Public Health, Primary Care, Orthopaedics, Otolaryngology, Ophthalmology, Anaesthetics and Intensive Care. In Trinidad and Tobago, medical graduates are given provisional registration by the MBTT and are allowed to practice under supervision as MIs at public healthcare facilities for one year. Medical interns rotate in threemonth cycles between Medicine, Surgery, Obstetrics and Gynaecology, and Paediatrics at public hospitals. Successful completion of the internship allows full registration and the transition from MI to $\mathrm{HO}$; HOs are subsequently assigned to a medical or surgical department at a hospital. Additional attachments may include Paediatric and Adult Emergency Departments.

Although a substantial amount of basic and clinical pharmacology is taught during the Paraclinical Sciences year, prescription writing skills are not included in the curriculum during this period. Oshikoya and colleagues assert that medical students should be sufficiently trained and assessed in fundamental aspects of CPT, especially as it relates to basic prescribing knowledge and skills during their formal undergraduate years to minimize future prescribing errors (1).

The medical curriculum at the St Augustine campus does not include a dedicated course in CPT, but elements are dispersed throughout the curriculum which may not provide students with "core knowledge and understanding, skills and attitudes concerning the use of drugs" and "core drugs and therapeutic problems for the medical curriculum" (13). The current situation suggests that the inclusion of a dedicated course in CPT be considered by the faculty to prepare graduates for efficient prescribing. Both MIs and HOs reported that they were sufficiently confident to prescribe although they were not assessed on principles of rational prescribing, drug dose calculation and pharmacovigilance at any point in time during their undergraduate training.

The General Medical Council in the UK emphasizes, "Medical schools have a responsibility to the public, employers and the profession to ensure that graduates are fit to practice" (14). Subsequently, prescribing skills and therapeutics are important themes that should run vertically and horizontally throughout the medical curriculum. It is advised that these elements should be assessed in the final year prior to graduation to detect poor knowledge about drugs and deficiencies in prescribing skills (15). 
Ideally, the "Core Curriculum for Tomorrow's Doctors" (16) and the General Medical Council (15) recommend that modes of assessment should test knowledge, skills and attitudes applied to a generic student formulary detailing the drug name, drug class, indication, alternatives, route and dose, monitoring, duration, elimination, adverse effects and interactions, while considering patients' characteristics and profile relative to drugs (17).

Prescribing is a complex task that requires sound theoretical knowledge and practical skills. Targeted teaching of these skills should lead to improvements in prescribing ability and confidence (8). The clinical skill of making an accurate diagnosis and individualized drug treatment(s) to fit the specific patient is more crucial today as the armory of available drugs keeps expanding (18). Perhaps this deficiency in practical skills training at the St Augustine campus may have accounted for the high levels of reluctance by both MIs and HOs to prescribe certain classes of drugs such as antiarrhythmics, antipsychotics, thrombolytics, hypnotics, anti-thyroid drugs, antivirals, anticonvulsants, antiparkinsonism drugs, antidepressants and anxiolytics. This reinforces the importance of developing teaching and assessments for prescribing in the curriculum, which may improve patient safety and certification of practical prescribing competency for medical students prior to graduation (19).

\section{Limitations of the study}

Our study had a few limitations. The study sought to estimate the percentage of newly registered MIs and HOs who claim to be confident to write prescriptions. However, attempts to obtain the lists of MIs and HOs from several sources were unsuccessful. Consequently, convenience sampling was used to the preferred simple random sampling or stratified sampling. Given that the sample size calculations were based on simple random sampling, the actual error bound of estimators cannot be determined. Also, the fact that over a quarter of the questionnaires were not returned added to the limitations of the study, especially as there are no data available for profiling the respondents. The questionnaire was not designed to measure the objective skills of HOs and MIs, ie testing the ability to write a prescription. Consequently, it was not possible to estimate prescribing errors by junior physicians and match these errors to self-reported confidence with competence to write prescriptions.

\section{CONCLUSIONS}

Our study suggest a curriculum review which should include the teaching of CPT in order to incorporate the essential skills of safe and rational prescription writing. Future plans are to design a study which would objectively measure the ability of physicians to write prescriptions.

\section{ACKNOWLEDGMENTS}

The authors wish to thank Dr George Legall, Department of Paraclinical Sciences, and Dr Trevor Alleyne, Department of
Preclinical Sciences, Faculty of Medical Sciences, The University of the West Indies, St Augustine campus for their critical analysis and review of this article. The authors report no declaration of interest.

\section{REFERENCES}

1. Oshikoya KA, Senbanjo IO, Amole OO. Interns' knowledge of clinical pharmacology and therapeutics after undergraduate and on-going internship training in Nigeria: a pilot study. BMC Med Educ 2009; 9: 50.

2. Coombes ID, Mitchell CA, Stowasser DA. Safe medication practice: attitudes of medical students about to begin their intern year. Med Educ 2008; 42: 427-31.

3. Garbutt JM, Highstein G, Jeffe DB, Dunagan WC, Fraser VJ. Safe medication prescribing: training and experience of medical students and house staff at a large teaching hospital. Acad Med 2005; 80: 594-9.

4. Bates DW, Cullen DJ, Laird N, Petersen LA, Small SD, Servi D et al. Incidence of adverse drug events and potential adverse drug events. Implications for prevention. ADE Prevention Study Group. JAMA 1995; 274: 29-34.

5. Akici A, Gören MZ, Aypak C, Terzioğlu B, Oktay, S. Prescription audit adjunct to rational pharmacotherapy education improves prescribing skills of medical students. Eur J Clin Pharmacol 2005; 61: 643-50.

6. Sandilands EA, Reid K, Shaw L, Bateman DN, Webb DJ, Dhaun N et al. Impact of a focused teaching programme on practical prescribing skills among final year medical students. Br J Clin Pharmacol 2011; 71: 2933.

7. Richir MC, Tichelaar J, Stanm F, Thijs A, Danner SA, Schneider AJ et al. A context-learning pharmacotherapy program for preclinical medical students leads to more rational drug prescribing during their clinical clerkship in internal medicine. Clin Pharmacol Ther 2008; 84: 513-6.

8. Likic R, Maxwell SR. Prevention of medication errors: teaching and training. Br J Clin Pharmacol 2009; 67: 656-61.

9. Leape LL, Bates DW, Cullen DJ, Cooper J, Demonaco HJ, Gallivan T et al. Systems analysis of adverse drug events. ADE Prevention Study Group. JAMA 1995; 274: 35-43.

10. Dean B, Schachter M, Vincent C, Barber N. Causes of prescribing errors in hospital inpatients: a prospective study. Lancet 2002; 359: 1373-8.

11. Heaton A, Webb DJ, Maxwell SR. Undergraduate preparation for prescribing: the views of 2413 UK medical students and recent graduates. Br J Clin Pharmacol 2008; 66: 128-34.

12. Tobaiqy M, McLay J, Ross S. Foundation year 1 doctors and clinical pharmacology and therapeutics teaching. A retrospective view in light of experience. Br J Clin Pharmacol 2007; 64: 363-72.

13. Maxwell SR, Cascorbi I, Orme M, Webb DJ. Joint BPS/EACPT Working Group Safe Prescribing. Educating European (junior) doctors for safe prescribing. Basic Clin Pharmacol Toxicol 2007; 101: 395-400.

14. General Medical Council. Medical students: professional values and fitness to practise; 2009 [cited 3 Dec 2012]. Available from: http://www. gmc-uk.org/static/documents/content/GMC_Medical_Students.pdf

15. Webb DJ, Maxwell SR. A spoonful of sugar? Tomorrow's Doctors 2002. Br J Clin Pharmacol 2002; 54: 341-3.

16. Maxwell S, Walley T. Teaching safe and effective prescribing in UK Medical schools: a core curriculum for tomorrow's doctors. Br J Clin Pharmacol 2003; 55: 496-503.

17. O’Shaughnessy L, Haq I, Maxwell S, Llewelyn M. Teaching of clinical pharmacology and therapeutics in UK medical schools: current status in 2009. Br J Clin Pharmacol 2010; 70: 143-8.

18. Report X Contemporary Issues in Medicine: education in safe and effective prescribing practices. Medical School Objectives. Washington DC: Association of American Medical Colleges; 2008 [cited 2012 Dec 3]. Available from: https://members.aamc.org/eweb/upload/Contemporary $\% 20$ Issues $\% 20 \mathrm{in} \% 20$ Education $\% 20 \mathrm{In} \% 20 \mathrm{Safe} \% 20$ and $\%$ Effective\%20Report\%X.pdf

19. Ross S, Loke YK. Development of learning outcomes for an undergraduate prescribing curriculum (British Pharmacological Society prescribing initiative). Br J Clin Pharmacol 2010; 70: 604-8. 